\title{
Gestão por Perversão: A crise econômica invade o Ambiente Organizacional e abre as portas ao Assédio
}

\begin{abstract}
Ismael de Mendonça Azevedo ${ }^{1}$
Resumo: A crise econômica torna a expectativa de vida financeira de uma organização algo incerto como também o ambiente interno da organização se torna instável e inseguro. Com o intuito de se manterem vivas, ativas e representativas, as organizações não perdem a audácia no momento em lançam novas metas para seus colaboradores, por vezes inalcançáveis, haja vista a instabilidade econômica. O objetivo deste trabalho é relatar a percepção das experiências de assédio moral vivenciadas por uma equipe de trabalhadores terceirizados de uma Instituição Bancária Federal. Para alcançar esse objetivo, revisou-se a bibliografia que define o clima organizacional e o assédio moral. A coleta de dados foi efetuada a partir de conversas informais com membros da equipe atuante no estado do Rio Grande do Norte, bem como observação e leitura de e-mails enviados e recebidos pelos mesmos com seus superiores diretos e indiretos. Finalizando com uma reflexão da perversão trazida pela crise ao ambiente organizacional.
\end{abstract}

Palavras-chave: Assédio moral; Recursos Humanos; Gestão de Pessoas; Psicologia Organizacional.

\section{Management Perversion: the Economic Crisis invades Organizational Environment and opens doors to Harassment}

\begin{abstract}
The economic crisis makes the expected financial life of an organization something uncertain as well as the organization's internal environment becomes unstable and insecure. In order to stay alive, active and representative organizations do not lose courage when launching new targets for its employees, sometimes unachievable, given the economic instability. The objective of this study is to report the perception of bullying experiences lived by a team of outsourced workers of a Federal Banking Institution. To achieve this goal, we revised to literature that defines the organizational climate and bullying. Data collection was conducted from informal conversations with members of the active team in the state of Rio Grande do Norte, as well as observation and emails sent and received reading the same with its direct and indirect superiors. Ending with a reflection of perversion brought the crisis to the organizational environment.
\end{abstract}

Keyword: People management; Human Resources; Harassment; Perversion; Organizational psychology.

\footnotetext{
${ }^{1}$ Bacharel em Administração pela Universidade Estadual da Paraíba, Campina Grande/PB, Brasil. MBA em Gestão de Pessoas pela Universidade Potiguar, Mossoró/RN, Brasil. Coordenador de Unidade no Instituto Nordeste Cidadania, Mossoró/RN, Brasil.

E-mail: ismaeldemendonca@bol.com.br
} 
Id on Line Revista Multidisciplinar e de Psicologia

Id on Line Multidisciplinary and Psycology Journal

\section{Introdução}

O mercado se tornou um ambiente hostil ao longo de sua história. Tal agressividade é representada pela grande concorrência que se instaurou por todos os lados com diversas empresas capazes de dispor dos mesmos produtos ou serviços, todos com um mesmo nível de qualidade e eficiência. Essa pluralização e especialização dos produtos e dos canais de vendas dos mesmos, acrescidos de um dinâmico processo de criação e geração de valor tornou o ambiente interno das organizações um lugar ativo onde o tempo e a gestão do capital tem sido um balizador nas relações, porém, acidentalmente como um agravante nas relações impessoais, sobretudo entre empregador e empregado.

A acirrada busca em direção ao topo da representação do mercado para se tornar a melhor empresa no segmento, agravada no Brasil pela crise econômica instalada e ainda sem expectativas de desaparecer, fez por evidenciar um modelo de gestão que é um contraponto a toda discussão sobre gestão da qualidade de vida no trabalho, a gestão por perversão, representada pela gestão com assédio moral. A história do assédio moral se confunde com a própria história do trabalho e suas relações. Data de 1976 a utilização do primeiro termo que em português traduzimos por assédio, harassment, utilizado por Brodsky do contexto de assédio sexual (SOARES, 2012). A disciplina Psicologia do Trabalho certamente foi um vetor importante para que na segunda metade do século passado houvesse a institucionalização do tema 'sofrimento no trabalho', especialmente, o de natureza mental (BENDASSOLLI, 2011).

Embora o assédio moral seja um assunto recorrente dentro do sofrimento no trabalho, somente no final do século XIX que fora identificado como algo destruidor do ambiente organizacional, no qual o alvo é o próprio indivíduo com um interesse mais ou menos consciente de prejudicá-lo, provocando uma destruição psicológica (HIRIGOYEN, 2015). Esse aspecto nas atuais organizações as faz empresas que vêm se tornando cada vez mais exigentes e duras, cobrando mais e mais de seus trabalhadores e, para isso, recorrem à gestão por meio de pressão (SOARES; VILLELA, 2012). Isso se dá em função da ambição por mercados nacionais e internacionais, aumento da competitividade perante a concorrência e pela própria sobrevivência das organizações (MARTININGO FILHO; SIQUEIRA, 2008). 
Diante do exposto, esse estudo tem por objetivo relatar a percepção das experiências de assédio moral vivenciadas por uma equipe de trabalhadores terceirizados de uma Instituição Bancária Federal.

No primeiro momento será apresentada uma revisão bibliográfica acerca de importantes fatores organizacionais como o clima organizacional e sua influência na motivação, posterior a esses, estará sendo apresentada uma revisão acerca do método mais comum de perversão, o assédio moral; finalizando com uma reflexão sobre a gestão por perversão no ambiente organizacional agravada pela crise econômica.

\section{Revisão da Literatura}

As empresas podem ser entendidas pela visão das pessoas, que tem respostas complexas, com reações biológicas, psicológicas e sociais que reagem simultaneamente às condições de vida no trabalho. Em cada pessoa na empresa fica intrínseca a possibilidade de reprodução subjetiva, recriação da própria empresa, que é balizado pelo contrato psicológico ali estabelecido que se constroi mediante a influência normativa da satisfação das necessidades de uma ou mais partes. No contrato entre pessoa e empresa os aspectos envolvidos são as habilidades, a performance e as características pessoais, os sistemas, as políticas e os serviços organizacionais (LIMONGI-FRANÇA, 2006).

O bem-estar do trabalhador é um resultado que deveria ser tão ou mais valorizado quanto o desempenho dos resultados capitais da organização. A discussão central nos dias atuais no qual o estresse e a qualidade de vida no trabalho são fatores preponderantes é decorrente do poder que os mesmos têm de impactar negativamente tanto nos indivíduos como nas organizações. Parte-se da gênese que estresse é o processo por meio do qual os estímulos ambientais desencadeiam reações mais ou menos permanentes nos indivíduos (PUENTEPALACIOS et al., 2013). Os efeitos inicialmente ocorrem em nível de sujeito, porém podem atingir o ambiente e os resultados de toda a organização, desencadeando, por exemplo, um clima organizacional empobrecido ou efetividade organizacional diminuída (PEIRÓ, 2009; PUENTE-PALACIOS et al., 2013). 
Id on Line Revista Multidisciplinar e de Psicologia

Id on Line Multidisciplinary and Psycology Journal

A melhoria no clima organizacional evidencia a busca por valores humanos, e traz a ideia de que o indivíduo não é apenas um funcionário, mas um sujeito que caminha lado a lado com os objetivos e o desenvolvimento organizacional. Um ambiente saudável apresenta características de valores como honestidade e integridade em tudo o que todos dizem e fazem. A comunicação é multidirecional, os gestores estão dispostos a ouvir o ponto de vida dos outros, especialmente dos subordinados. Se o clima organizacional for bom, os indivíduos tendem a ser proativos, partilhar conhecimentos, confiar nos chefes, colegas e subordinados, em contrapartida se for um ambiente organizacional de clima ruim, as pessoas tendem a fazer o mínimo possível para se manter no emprego, às vezes agindo com descrença e revolta, aumentando a rotatividade e o absenteísmo, que com frequência, são sintomas de clima organizacional negativo (SOARES, 2014).

Em decorrência das exigências do mundo do trabalho a promoção de um adequado clima organizacional e percepção de qualidade de vida no contexto laboral facilitariam as condições de trabalho. As organizações estão se preocupando afinco na promoção da qualidade de vida dos colaboradores para uma maior gestão dos conflitos, resultados, redução do absenteísmo e doenças relacionadas ao trabalho. A discussão desse contexto de qualidade de vida no trabalho não é algo novo, na atualidade as instituições implantam e revisam com maior frequência tais programas como um diferencial, visando maior competitividade em relação às demais organizações (HUANG et al., 2007; LEITE et al., 2009; TIMOSSI, 2009; RUEDA et. al., 2013).

Investir no clima organizacional é investir nas pessoas. $\mathrm{Na}$ era industrial os fatores que predominavam na produção eram basicamente o capital e a mão de obra, entretanto, hoje na era do conhecimento esses fatores não são os únicos pertinentes. Atuar com investimentos em pessoas é a tendência para as organizações bem sucedidas, visto que os fatores críticos relacionados ao sucesso estão ligados à agilidade com que os indivíduos têm em transmitir respostas e inovações em produtos e serviços. Os colaboradores tem em sua natureza psicossocial uma complexidade na maneira de se ver, e nas formas de interpretar o meio externo a si, levando para a sua cognição o ver, o sentir, e o perceber o mundo. Dentre os fatores intrínsecos a cada indivíduo e que influenciam em seu comportamento, podemos destacar a motivação como fator que corresponde ao impulso que leva o indivíduo a agir de determinada forma (CHIAVENATO, 2015; BRAGA JUNIOR et al., 2013). 
Em favor da motivação ou contra a mesma, é possível identificar o estresse no ambiente de trabalho como um aspecto relacionado ao clima organizacional, que pode influenciar e funcionar como um catalizador de sentimentos e ações para uma melhor prática, atenção e dinamismo relacionada a tarefa prática no trabalho, ou, influenciar para um desgaste emocional no ambiente de trabalho. $\mathrm{O}$ estresse é um estado relativo à tensão que causa ruptura com a homeostase do organismo, que somatizado mediante a percepção da experiência individual de cada sujeito pode ocasionar boas experiências emocionais, ou más experiências. A relação distinta de cada colaborador ditará a expectativa do indivíduo mediante o estresse, que quando bem administrado pela empresa, se tona uma fonte de resiliência.

É necessário entender a percepção de estresse e assédio moral no ambiente organizacional de maneiras distintas. Pois devem ser excluídas das constatações objetivas e subjetivas dos indivíduos as situações de estresse causado por celeridade de tempo no labor de algum trabalho ou quando no exercício do poder diretivo do empregador. Sofrer por causa de um superior exigente, perfeccionista, discussões habituais, jogos de ideias diferentes, tensões e incidentes isolados não devem ser compreendidos com situações abusivas e que ferem o moral do trabalhador. Agressões desse tipo, pontuais, não repetitivas, são violências, contudo, não caracterizam assédio (GUIMARÃES; RIMOLI, 2006; HIRIGOYEN, 2015; LIMA et. al., 2014). Assédio moral é um processo de grave violência psicológica no contexto de trabalho, produz efeito de humilhação, ofensa e constrangimento. São práticas corriqueiras, perturbadoras, rudes, hostis, verbalizadas em gestos ou palavras, escritas ou faladas, comportamentos explícitos, camuflados ou silenciosos (SOBOLL, 2011).

$\mathrm{O}$ excesso de cobranças por eficiência e produtividade em momentos de crise acaba acarretando compulsão e desejo de superação dos objetivos organizacionais e realização profissional. $\mathrm{Na}$ ausência do retorno esperado surgem atitudes negativas no ambiente como insegurança, ausências no trabalho, isolamento, agressividade, irritabilidade, depressão (LIMONGI-FRANÇA; RODRIGUES, 2012; REATTO et. al., 2014). É nesse contexto de insatisfação com os resultados operacionais que ocorre o surgimento das agressões. Dessa forma, não se trata necessariamente de melhorar a produtividade ou aperfeiçoar os resultados, mas se livrar de um sujeito porque de alguma maneira ela incomoda (HIRIGOYEN, 2015). O assédio ao trabalhador tem como característica mais marcante o objetivo de anular a 
Id on Line Revista Multidisciplinar e de Psicologia

Id on Line Multidisciplinary and Psycology Journal

subjetividade do indivíduo (REZENDE, 2006), a impossibilidade de realizar um trabalho bem feito, ou de debater sobre os critérios envolvidos no que se faz, impede o reconhecimento de si no próprio trabalho, tornando o trabalho estranho para si mesmo (BENDASSOLLI, 2011).

\section{Métodos}

O estudo se caracteriza como um relato descritivo de experiência de abordagem qualitativa (GIL, 2008). A escolha do público alvo para esse estudo se deu em função destes assumirem o papel de gestores locais em cada município no qual atuam. Tendo sob sua gestão uma jurisdição pertencente às respectivas agências bancárias a qual estão vinculados e que abrangem os 167 municípios do estado do Rio Grande do Norte. Para a escolha do público, também fora levado em consideração a vasta experiência em assumirem a responsabilidade de mediadores e atuarem no meio da pirâmide organizacional da empresa que os terceirizam, onde acima estão os gerentes e diretores, responsáveis por solicitar as demandas referentes aos objetivos, metas e anseios do banco, e na base da pirâmide estão os agentes e assistentes responsáveis pela busca direta na superação dos objetivos, metas e anseios daquela instituição Federal.

A instituição atua em toda região Nordeste brasileira, empregando cerca de 6.000 colaboradores, divididos entre diretores, gerentes, coordenadores, agentes, assistentes e funções técnicas. A equipe de coordenadores acompanhada e estudada atua exclusivamente no estado do Rio Grande do Norte e possui 27 coordenadores, dos quais 16 são homens e 11 mulheres, com uma média de idade de 33 anos e formação escolar entre ensino médio, graduados e especialistas, das mais diversas áreas do conhecimento, destacando a Área das Ciências Sociais Aplicadas como sendo a área mais evidenciada entre os portadores de diplomas desde nível.

A coleta de dados se deu a partir de conversas informais com os membros da equipe de coordenadores, bem como por meio de observação e leitura atenta de e-mails e mensagens enviadas e recebidas pelos mesmos, de seus superiores diretos e indiretos. Durante o trabalho buscou-se identificar as problemáticas vivenciadas pelo grupo em sua realidade de trabalho de maneira impessoal e imparcial, durante os meses de junho e dezembro de 2015. A construção 
Id on Line Revista Multidisciplinar e de Psicologia

Id on Line Multidisciplinary and Psycology Journal

do referencial teórico foi possível, sendo necessário para tanto, o levantamento de artigos e livros que subsidiassem a discussão e reflexão sobre a temática.

\section{Resultados e Discussões}

Evidenciaram-se diversas ocorrências de $e$-mails com conteúdos insinuantes, escritos com palavras e frases específicas que traziam em seu contexto mensagens subliminares, com intenções bem peculiares de intimidação percebida pelos colaboradores. Tais frases foram escritas em negrito, com variação de tamanho de fonte, de cor e outros tipos de destaque como imagens. Mensagens evidenciadas repetidas vezes em e-mails e mensagens de aplicativos diversos e distintos, algumas direcionadas a colaboradores específicos, outros direcionados ao grupo de maneira geral. Esse aspecto encontrado na organização é relevante para indicar um movimento que pode levar os colaboradores ao sentimento de coação e a um posterior sofrimento psíquico, de certo, perigoso para o adoecimento destes.

Houve ainda mensagens direcionadas a um indivíduo que fora disseminada pelo superior a mais de um colaborador, expondo uma realidade individual a todos. Um ato complexo, pois para Hirigoyen (2015), quando uma pessoa acredita estar na situação de 'bode expiatório' por causa de um superior hierárquico ou até mesmo de colegas, a qualificação rapidamente se alastra a todo o grupo e o indivíduo passa a ser apontado como sendo responsável por tudo que há de errado.

O planejamento estratégico é uma técnica administrativa muito usada pelos gestores de organizações para orientar os rumos de suas empresas. Tal planejamento aborda análises do ambiente onde a organização está situada, destaca entre outras coisas, as ameaças, oportunidades, pontos fortes e fracos, oportunizando que seja traçado ideias estratégicas para amenização de fatores que afetem negativamente a organização, bem como potencializando os fatores que favorecem um melhor aproveitamento do ambiente que a organização está inserida. Feito de maneira correta, o planejamento estratégico é uma ferramenta importante para a sobrevivência da organização neste mundo inconstante, é o esquema norteador das ações que irão manter ou elevar a empresa ao êxito (SAGGIN; RITTERBUCH, 2012). 
A não aceitação calorosa por parte da gerência das estratégias enviadas por parte da equipe ocasionou uma percepção de subutilização do capital intelectual dos coordenadores, o ato de não aceitar as discussões em busca de melhores propostas de trabalho e formas de superação dos resultados, ocasionou uma fragilidade no reconhecimento de si no trabalho, os colaboradores percebem a anulação das suas subjetividades. Não se pode determinar esse fator relatado por parte da equipe como sendo abuso de poder, mas é válido lembrar, assim como Hirigoyen (2015), que uma relação dominante-dominado, na qual aquele que comanda o jogo busca submissão do outro até fazê-lo perder a identidade, quando passa do âmbito de uma relação de subordinação é de fato visto como abuso de poder e o superior se torna a dominação da pessoa.

\section{Considerações Finais}

Os principais relatos encontrados nas conversas teciam sobre ao que resultou em perda de satisfação no trabalho por parte das equipes. Conclui-se que o assédio moral se apresenta como um despersonificador do sujeito no ambiente organizacional. A vivência contribuiu ainda para esclarecer dúvidas dos participantes quanto à diferenciação de estresse, cobranças por resultados e assédio moral. Tal experiência serviu, não apenas, para inserir os pesquisadores na realidade do trabalho com o fim de observar as influências de possíveis assédios em suas relações de trabalho, mas, principalmente, para propiciar a compreensão por parte da equipe quanto as suas relações de subordinação no trabalho enquanto processo dinâmico, complexo, que exige de quem está no meio da pirâmide, uma compreensão holística sobre as necessidades de quem está na base da pirâmide, como também de quem está no topo.

Diante dos elementos coletados no presente estudo, foi possível atingir e evidenciar o objetivo do trabalho quanto aos relatos e a percepção das experiências de assédio moral por parte dos colaboradores e quanto aos seus desempenhos profissionais e bem-estar psicológico, que sofrem prejuízos marcantes nas situações vivenciadas. Percebe-se, a partir dos e-mails e mensagens, bem como por relatos dos indivíduos que participaram da pesquisa, uma possível ocorrência de assédio moral. 
Id on Line Revista Multidisciplinar e de Psicologia

\section{Referências}

BENDASSOLLI, P. F. Mal estar no trabalho: do sofrimento ao poder de agir. Revista mal estar e subjetividade, Fortaleza, v. XI, n. 1, p. 65-99, 2011.

BRAGA JUNIOR, S. S et al.. Possibilidades entre motivação e produtividade: Um estudo de caso no alto Tietê. Rio de Janeiro, v. 8, n. 2, p. 90-104, 2013.

CHIAVENATO, I. Recursos Humanos. 10. ed. São Paulo: Campus, 2015.

GIL, A. C. Métodos e Técnicas de Pesquisa Social. 6. ed. São Paulo: Atlas, 2008.

GUIMARAES, L. A. M.; RIMOLI, A. O. Mobbing (assédio psicológico) no trabalho: uma síndrome psicossocial multidimensional. Psicologia teoria e pesquisa. Brasília, v. 22, n. 2, p. 183-192, 2006.

HIRIGOYEN, M. F. Mal-estar no trabalho: redefinindo o assédio moral. 8. ed. Rio de Janeiro: Bertrand Brasil, 2015.

HUANG, T. C. et al.. The effects of quality of work life on commitment and turnover intention. Social behavior and personality. New Zeland, v. 35, n. 6, p. 735-750, 2007.

LEITE, J. V. et al.. Mudando a gestão da qualidade de vida no trabalho. Psicologia: organizações e trabalhos. Brasília, v. 9, n. 2, p. 109-123, 2009.

LIMA, C. Q. B. et al.. Assédio moral e violência no trabalho: caracterização em perícia judicial. Relato de experiência no setor bancário. Rev. bras. saúde. ocup. São Paulo, v. 39, n. 129, p. 101-110, 2014.

LIMONGI-FRANÇA, A. C. Comportamento organizacional: conceitos e práticas. São Paulo: Saraiva, 2006.

LIMONGI-FRANÇA, A. C.; RODRIGUES, A. L. Stresse e trabalho: uma abordagem psicossomática. São Paulo: Atlas, 2012.

MARTININGO FILHO, A.; SIQUEIRA, M. V. S. Uma análise do assédio moral nas organizações e o papel da área de gestão de pessoas. Rev. adm. Mackenzie. São Paulo, v. 9, n. 5, p. 11-34, 2008.

PEIRÓ, J. M. Estrés laboral y riesgos psicosociales: investigaciones recientes para su análisis y prevención. Lección magistral leída en el solemne acto de apertura del curso 2009-2010, Universitat de Valencia, España, 2009. 
Id on Line Revista Multidisciplinar e de Psicologia

Id on Line Multidisciplinary and Psycology Journal

PUENTE-PALACIOS, K. E. et al.. Clima organizacional e estresse em equipes de trabalho. Revista psicologia: organizações e trabalho. Brasília, v. 13, n. 1, p. 37-48, 2013.

REATTO, D. et al.. Prevalência da síndrome de burnout no setor bancário no município de Araçatuba. Arch. health. invest. V. 3, n. 2, p. 1-8, 2014.

REZENDE, L. O. A deteriorização das relações de poder dentro do organismo empresarial: uma análise do assédio moral no contrato de trabalho. 2006. 177 f. Dissertação (Mestrado em Direito) - Setor de Ciências Jurídicas, Universidade Federal do Paraná, 2006.

RUEDA, F. J. M. et al.. Psicologia organizacional: associação entre qualidade de vida e clima organizacional. Encontro: revista de psicologia. Valinhos, v. 16, n. 24, p. 69-82, 2013.

SAGGIN, E.; RITTERBUCH, D. S. A importância do planejamento estratégico para as instituições financeiras. Revista de administração. Frederico Westphalen, v. 10, n. 17, p. 6070, 2012.

SOARES, A. As origens do conceito de assédio moral no trabalho. Rev. bras. saúde ocup. São Paulo, v. 37, n. 126, p. 284-286, 2012.

SOARES, J. J. Diagnóstico na área de Recursos Humanos e clima organizacional. Revista Diálogos Interdisciplinares. Paraná, v. 3, n. 2, p. 49-70, 2014.

SOARES, L. R.; VILLELA, W. V. O assédio moral na perspectiva de bancários. Rev. bras. saúde ocup. São Paulo, v. 37, n. 137, p. 203-212, 2012.

SOBOLL, L. A. P. Assédio moral no trabalho. In: CATTANI, A. D.; HOLZ- MANN, Lorena (orgs). Dicionário de Tecnologia e Trabalho. Porto Alegre: Editora da UFRGS, 2011.

TIMOSSI, L. A. Correlações entre a qualidade de vida e a qualidade de vida no trabalho em colaboradores das indústrias de laticínios. 2009, 173f. Dissertação (Mestrado em Engenharia da Produção) - Programa de Pós Graduação em Engenharia da Produção, Universidade Tecnológica Federal do Paraná, 2009.

\section{Como citar este artigo (Formato ABNT):}

AZEVEDO, I.M. Gestão por Perversão: A Crise Econômica invade o ambiente Organizacional e abre as portas ao Assédio. Id on Line Revista Multidisciplinar e de Psicologia, Nov-Dez. de 2016, vol.10, n.32, p. 189-198. ISSN: 1981 1179.

Recebido: 16/09/2016

Aceito: 21/09/2016 